\title{
LA MUJER EN EL MUNDO MEDIEVAL: UNA REFLEXIÓN SOBRE SUS CONQUISTAS Y MENTALIDADES
}

María Elena Chico de Borja

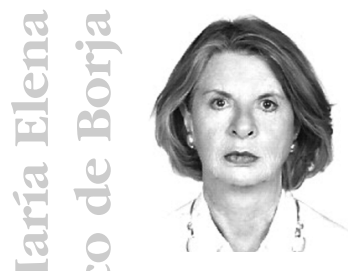

Doctora en Historia y directora académica de Proyección hacia Nuevas Fronteras. A lo largo de su carrera ha colaborado con el FONAES para capacitación a distintas comunidades y ha publicado diversas obras en las que destacan: Cancilleres de México, obra colectiva; Historia del Colegio de Notarios de 1972 a 1901 y de 1902 a 1980; El papel de la mujer en la Iglesia Medieval. Ha participado en diversos foros internacionales a favor de la mujer.

Correo electrónico:

Este estudio ${ }^{1}$, aceptando la periodización habitual de la historia occidental, se centra en la Edad Media y se concreta en los siglos X al XIII, en un espacio limitado: el mundo occidental, y ante todo, la Europa grecolatina y judeocristiana. Trata de destacar los nada desdeñables logros de una serie de mujeres de todas las categorías de la sociedad medieval, y se propone la reflexión sobre el papel y la importancia de la mujer en este período.

Chico de Borja, M.E. La Mujer en el mundo medieval. Siglos X a XIII., Ed. Porrúa., México., 2006. 
El primer objetivo de este trabajo fue probar cómo el cristianismo intentó romper, de alguna manera, con la subordinación de la mujer al varón que implicaba el patriarcado. La radical afirmación cristiana de la igualdad en dignidad del hombre y la mujer - aunque de muchas formas mejoró la situación femenina- no llevó a consecuencias jurídicas prácticas, sino que se mantuvo la subordinación de la mujer en la familia y en la sociedad.

Como afirma la maestra Blanca Castilla y Cortázar: «El pensamiento cristiano no fue lo suficientemente revolucionario, pues no llevó a sus últimas consecuencias el mensaje que predicó Jesucristo, y se plegó a los condicionamientos intelectuales y sociales de esquemas judíos y paganos".

Sin embargo, sí supuso una notable mejoría en la consideración y estatus personal, familiar y social de la mujer. Fue decisiva la influencia de esta religión en la defensa del derecho a la vida de los hijos, y en especial de las niñas; el respeto a los niños, a las mujeres y a los esclavos se fue extendiendo poco a poco. El matrimonio cristiano fue también una institución decisiva para mejorar la situación de la mujer en la familia y en la sociedad.

La Edad Media abarca un largo período de casi diez siglos, sus gentes vivieron circunstancias mentales, morales y físicas totalmente diferentes a las nuestras, hecho que no debemos perder de vista. Durante este período hubo muchos cambios intelectuales y sociales, e inevitablemente la posición de las mujeres reflejó las corrientes más amplias de la sociedad. La sociedad que del siglo X al XIII no dejó de cambiar y complicarse, también había cambiado y complicado la vida de las mujeres. De ahí que hablar de la mujer en la vida medieval 
representa un tema extremadamente complejo debido a la amplia gama de las actividades femeninas.

La sociedad medieval exhibía una presencia constante de lo femenino, aunque en algunas ocasiones subordinado a lo masculino, pero las más de las veces igual a él, y es indudable la contribución de la mujer a la cultura y al crecimiento y desarrollo de la propia sociedad.

La vida social de la mujer se desarrolló en la cotidianidad, en los múltiples trabajos domésticos que realizó, pues el trabajo femenino no se limitaba sólo a lo estrictamente doméstico (aunque se desenvolvía la mayor parte de las veces dentro de las unidades familiares). Resulta muy reveladora la frase de Roberto Fossiser: "Es evidente que la célula esencial de la vida es la casa, y si es cierto que la mujer reina en ella, es ella y no el hombre quien ocupa el centro de la sociedad".

La actividad primordial de la mujer giraba alrededor de su familia, formada en la época feudal y medieval por el conjunto de personas que vivían en el mismo hogar, cortando el mismo pan y bebiendo del mismo recipiente. A ella le correspondía la crianza y la educación de los hijos, así como la organización y administración del hogar. En épocas de guerras y conflictos, el ama de casa debía ocuparse, además, de defender su casa y sus propiedades, sembrar y cosechar los campos, cuidar el ganado..., en fin, de dirigir que todo marchara bien hasta el regreso del esposo.

Hubo sin embargo, actividades estimadas propias de la mujer, como las relacionadas con la elaboración de alimentos, la educación, el cuidado de los enfermos o la industria textil. 
Las mujeres trabajaron en multitud de oficios. En las ciudades se conservan testimonios de la existencia de taberneras, cocineras, bordadoras, lavanderas, administradoras de hospitales o cárceles, joyeras, fruteras, pescaderas, etcétera.

Las mujeres participaron también, activamente, en la medicina, la literatura y la música. Existieron numerosos monasterios y abadías femeninas que tenían un alto nivel cultural y que eran, además, escuelas de niños y niñas de familias nobles. Las religiosas dirigieron monasterios y abadías, hospederías, leproserías y hospitales, y encontraron en los conventos un lugar propicio para su desarrollo y crecimiento personal. Las abadesas no sólo eran educadoras y protectoras de la cultura, algunas también fueron creadoras notables; el primer gran nombre de la literatura alemana en el siglo $\mathrm{X}$ es Hroswitha de Gandersheim; en el siglo XII, recordamos a Herrada de Landsberg y a Hildegarda de Bingen.

El poder de las abadesas y sus atribuciones, en especial su competencia para la administración de bienes, indica que algunas eran auténticas señoras feudales de gran autoridad, lo que determinaba que su actividad se proyectara en la vida civil y en el ámbito jurídico, como foco de donaciones o de percepción de rentas. Tenemos, entre otros varios, el monasterio de Hefta — sin duda el más floreciente de Alemania—, lugar donde destacaron las dos Matildes: Matilde de Hackeborn y Matilde de Magdeburgo, y Santa Gertrudis la Magna.

En España, está el Real Monasterio de Santa María de las Huelgas, fundado por Alfonso VIII y la reina Leonor en 1187, y cuyas abadesas gozaron de un gran poderío civil, unido a una intensa vida espiritual y un importante desarrollo intelectual. 
Hemos dedicado un apartado especial a Hroswitha, canonesa de Gandersheim, del siglo X, poeta, escritora e historiadora sajona, la primera autora occidental que adaptó el drama y la poesía clásica a temas cristianos, su influencia llega hasta nuestros días; y a Hildegarda de Bingen, abadesa benedictina alemana del siglo XII, artista cuya música se ha podido rescatar. Visionaria, escritora, compositora, herbolaria, médico y consejera de Papas y emperadores. Fue una mujer a la que se le reconoció autoridad en materia de doctrina cristiana; recibió autorización explícita del Papa para escribir obras teológicas, gozó del privilegio de predicar en iglesias y plazas, y fue autora de una pieza dramática moral y de una vasta obra de carácter enciclopédico.

Un lugar preferente durante la época medieval lo ocuparon las reinas, las reinas consortes, las infantas y un sinfín de mujeres que participaron activamente en el poder político. Demostramos que estas mujeres no sólo sirvieron como parte de la negociación de las alianzas entre los reinos durante el proceso de normalización política (especialmente en los siglos XII y XIII y comienzos del XIV), sino que tuvieron en este proceso de pacificación espacios propios de participación; no sólo con base en sus derechos, sino que supieron aprovechar - e incluso crear- el poder suficiente para ejercer una influencia real y generalmente benéfica.

Además de Leonor de Aquitania y Blanca de Castilla (a quien dedicamos un capítulo aparte), cabe mencionar la labor de muchas otras nobles mujeres como la reina Tamara de Georgia; dos poderosas terratenientes inglesas: Nicolaa de la Haye e Isabel de Fortibus; y la gran Matilde di Canosa, que defendió al Papa Gregorio VII del emperador de Alemania Enrique IV. 
El objetivo de este trabajo es llevarnos a un mejor conocimiento del lugar que ocupó la mujer en los siglos X-XIII. La idea, muy extendida, de referirse a esos años como "época oscurantista" o "las tinieblas de la Edad Media", hace suponer que la mujer carecía de oportunidades para desarrollarse cuando, al contrario, queda a la mujer, como afirma Régine Pernoud: "[...] mucho camino que recorrer para recobrar el puesto y la dignidad que tuvo en tiempos de una Blanca de Castilla o una Leonor de Aquitania” ${ }^{2}$.

Nos preguntamos, a veces, si el actual esfuerzo por liberar a la mujer, no corre el riesgo de fracasar, porque señala una tendencia suicida para ella: negarse en tanto mujer, conformarse con copiar las conductas del hombre, tratar de reproducirlo como una especie de modelo ideal y perfecto, negándose su propia identidad.

Me atrevo a asegurar que este trabajo nos ayudara hoy, en este nuevo milenio, a la formación de un verdadero feminismo integral; a rescatar la dignidad de la mujer; su igualdad en la diferencia; su identidad específica hasta aceptar su genio, recuperar su feminidad y, como afirmó Karol Wojtyla, descubrir aquel espíritu misterioso, "carisma de las mujeres". Concluyo con unas palabras del gran filósofo español Julián Marías: "[es fundamental] buscar que la mujer vuelva a ser el gran motor de perfección del mundo, tome posesión de la realidad, desde su perspectiva original, desde su condición irrenunciable, única, de persona femenina".

Pernoud, Régine., Edad Media. La mujer sin alma., pp. 139-156. 